\title{
Retrospective Survey of Pediatric Diabetics at a Tertiary Healthcare Center in Uyo, South-South Nigeria
}

\section{Olufisayo Gabriel Ayoade ${ }^{1}$, Collins Amadi ${ }^{1, ~ *, ~ S u n d a y ~ B a b a t u n d e ~ A d e s i n a ~}{ }^{3}$, Sarah Ifreke Essien², Enobong Nkereuwem Udoh ${ }^{1}$, Ofonmbuk Okon Umoh ${ }^{1}$}

${ }^{1}$ Department of Chemical Pathology, University of Uyo Teaching Hospital, Uyo, Nigeria

${ }^{2}$ Department of Chemical Pathology, University of Uyo, Uyo, Nigeria

${ }^{3}$ Department of Pediatrics, University of Uyo Teaching Hospital, Uyo, Nigeria

\section{Email address:}

collins338@yahoo.com (C. Amadi)

${ }^{*}$ Corresponding author

\section{To cite this article:}

Olufisayo Gabriel Ayoade, Collins Amadi, Sunday Babatunde Adesina, Sarah Ifreke Essien, Enobong Nkereuwem Udoh, Ofonmbuk Okon Umoh. Retrospective Survey of Pediatric Diabetics at a Tertiary Healthcare Center in Uyo, South-South Nigeria. American Journal of Pediatrics. Vol. 6, No. 3, 2020, pp. 327-333. doi: 10.11648/j.ajp.20200603.36

Received: July 10, 2020; Accepted: July 29, 2020; Published: August 18, 2020

\begin{abstract}
Purpose: Despite the high prevalence of diabetes mellitus (DM) reported among adult Uyo inhabitants in southsouth Nigeria, no data exist on pediatric DM (PDM) to date. Hence, the current study aimed to evaluate pediatric subjects diagnosed with DM in Uyo, South-south Nigeria. Methods: This was a retrospective survey of incident/newly diagnosed PDM subjects diagnosed/managed over 15 years (2003-2018) at the University of Uyo Teaching Hospital (UUTH), South-south Nigeria. Patients' demographic, clinical, and laboratory variables at PDM diagnosis were retrieved from medical records and analyzed using descriptive statistics. Results: 45,551 pediatric cases were managed during the studied period among them 9 PDM cases, all of type $1 \mathrm{DM}$, giving PDM prevalence of $0.20 / 1000$. Age at diagnosis was $7.00 \pm 4.82$ years (range 2-16) with a predominance of $\leq 5$-year-olds $(44.4 \%)$ and females $(66.6 \%)$. Most $(77.8 \%)$ presented via the pediatric outpatient clinic, during the rainy season $(55.6 \%)$, were urban-dwellers $(55.6 \%)$, of Ibibio ethnicity (55.6\%), and lower socioeconomic status $(44.4 \%)$. Three (33.3\%) had DM family history, mostly in first-degree $(\mathrm{n}=2)$ relatives. Predominant symptoms were polyuria $(100 \%)$, polydipsia (100\%), weight loss $(88.9 \%)$, and weakness $(77.8 \%)$; polyuria being the most prolonged symptom. Three $(33.3 \%)$ were underweight/stunted, and $2(22.2 \%)$ were overweight. DKA complicated with AKI and dehydration-induced AKI was recorded in 2 respective cases. The default rate to follow-up was discouragingly high following diagnosis. Conclusion: The prevalence rate of PDM was relatively low, occurred mostly among the $\leq 5$-year-olds, with a high rate of default to follow-up. These findings could serve as health policy targets by various stakeholders within the studied region.
\end{abstract}

Keywords: Diabetes, Pediatric Diabetes, Pediatric Type 1 Diabetes

\section{Introduction}

In parallel to the increasing global burden of diabetes mellitus (DM) among the adult populations in recent times, the burden of the disease among the pediatric populations has also posed a major public health concern. [1] Consequently, recent epidemiologic evidence has documented an increasing burden of the metabolic disorder among the pediatric age-group with regards to the disease incidence, prevalence, morbidity, and overall mortality. [1-3]

Historically, type 1 DM (T1DM) was adjudged as the predominant pediatric age-group DM type, however, recent findings also indicate an increasing trend of type $2 \mathrm{DM}$ (T2DM) among the pediatric populations. [3, 4] Etiologically, while TIDM undoubtedly has genetic attributes in association with some environmental triggers, the global overweight and obesity epidemic has been linked with the rising T2DM burden among the pediatric age-group populations. [1]

In Nigeria, a similar trend of worsening DM epidemiologic indices, especially of the T1DM variant, among the pediatric populations has also been reported from different regions of 
the country in few published data. [5-13]

Uyo, the capital city of Akwa Ibom State in the Southern part of Nigeria, has been reported to have one of the highest adult DM prevalence rates in the country. $[14,15]$ However, no published data to date has been documented on DM among the pediatric populations in Uyo, South-south Nigeria. Hence, the current study aimed to evaluate subjects diagnosed with pediatric DM (PDM) in the University of Uyo Teaching Hospital, South-south Nigeria.

\section{Materials and Methods}

\subsection{Design and Site}

This study is a retrospective, descriptive, and crosssectional hospital-based review of records of pediatric subjects diagnosed with DM over 15 years (2003-2018) at the University of Uyo Teaching Hospital (UUTH). UUTH is a tertiary medical facility located in Uyo, Akwa Ibom State, South-south Nigeria. The hospital is a major referral center for the primary, secondary, and other privately-owned healthcare facilities in Akwa Ibom State and its neighboring states. The hospital is well-equipped and adequately-staffed with various specialized Departments (outpatient, family medicine, internal medicine, obstetrics/gynecology, chemical pathology, pediatrics, health information management, etc).

\subsection{Ethical Considerations}

The study protocols conformed to the ethical guidelines of the 1975 Declaration of Helsinki and ethical approval was obtained from the Research Ethical Committee of UUTH. Written informed consent was waived owing to the solely databased design of the study. All data was anonymized and treated with the utmost confidentiality. Permission was also obtained from the heads of relevant departments before commencement.

\subsection{Study Instruments}

The study instruments consisted of updated hospital data of each case in the Department of Health Information Management of UUTH of all eligible PDM patients within the study period.

\subsection{Eligibility Criteria}

The criteria for inclusion included records of pediatric diabetic patients aged $\leq 18$ years of age who were diagnosed and managed, including those referred and later confirmed, in UUTH between the $1^{\text {st }}$ of January 2003 and $31^{\text {st }}$ December 2018. The criteria for exclusion included records of those with incomplete data and records of DM cases who are older than 18 years, pregnant patients, and those diagnosed outside the study period.

\subsection{Data Acquisition}

Relevant data were acquired from medical records from the Department of Health Information Management using the trained resident doctors from the Department of Chemical
Pathology as research assistants.

The variables which data was collected at DM diagnosis included the followings: the number of all pediatric cases seen within the study period, number of PDM cases, DM type, age, sex, place of residence, tribe, educational/occupation of patients if any, occupation of parents/guardians, social class of parents/guardians, family history of diabetes, month diagnosed, year diagnosed, mode of presentations, weight at diagnosis, height at diagnosis, calculated height for age (HA), weight for age (WA), weight for height (WH) and body mass index (BMI) Z scores, clinical features (symptoms/signs), duration of clinical features, vital signs (temperature, heart and respiratory rates), co-morbid conditions, glycemic status, and urinalysis (glucose, proteins, ketones, blood, $\mathrm{PH}$, specific gravity) findings. Survey pro forma with columns under the earlier mentioned major variable headings was utilized for the data acquisition from all the identified eligible PDM cases.

\subsection{Specimen Collection/Biochemical Determinations}

During the study period, all specimen collection and biochemical analysis had been done based on standard protocols and guidelines. Plasma glucose and the urine biochemical parameters were determined using the glucose oxidase/peroxidase principle and dipsticks, respectively.

\subsection{Data Definitions and Stratifications}

In the study center, the diagnosis of PDM is made by the specialist pediatricians based on the International Society for Pediatric and Adolescent Diabetes (ISPAD) consensus guidelines. [1]

In the current study, identification of TIDM cases was based on a detailed review of medical history, patient characteristics, classics clinical features (polyuria, polydipsia, polyphagia, weight loss, etc), laboratory findings, persistent usage of, and response to, insulin therapy for at least a year following diagnosis.

Diabetic ketoacidosis (DKA) was diagnosed in the presence of hyperglycemia of $>11.1 \mathrm{mmol} / 1$, plasma bicarbonate level of $<15 \mathrm{mmol} / 1$ with ketonuria based on the ISPAD guidelines. [16] Acute kidney injury (AKI) was defined by the Kidney Disease/Improving Global Outcomes (KDIGO) serum creatinine criteria. [17] The baseline creatinine was determined following the steps detailed by Hursch et al. [18] Anthropometric $\mathrm{Z}$ scores were determined using the World Health Organization (WHO) recommended computer software $[19,20]$ The WHO Anthro for personal computer software version 3.22 was used for age-group 0-5 years. [19] While the WHO AnthroPlus for personal computer software version 1.04 was used for the age-group 5-18 years. [20] The $\mathrm{Z}$ scores were stratified based on the WHO guidelines. [19, 20]

HA Z score was stratified as normal $(>-2)$, moderately stunted $(-3$ to $\leq-2)$, and severely stunted $(\leq-3.0)$ among the age-groups $0-5$ and $5-18$ years. WA $Z$ score was stratified as normal $(>-2)$, moderately underweight $(-3$ to $\leq-2)$, severely underweight $(\leq-3.0)$ among the age-group $0-10$ years. WH Z 
score was stratified as normal $(>-2$ to $\leq+1)$, moderately wasted $(-3$ to $\leq-2)$, severely wasted $(\leq-3)$, overweight $(+1$ to $\leq+2)$, and obese $(\geq+2)$ among the age-group $0-5$ years. BMI $\mathrm{Z}$ score was stratified as eutrophic $(>-1$ to $\leq+1)$, moderately wasted $(-3$ to $\leq-2)$, severely wasted $(\leq-3.0)$, overweight $(+1$ to $\leq+2)$, and obese $(\geq+2)$ among the age-group 5-18 years.

The socio-economic status (SES) of parents and/or their guardians was determined using the highest educational attainment and occupation of both parents/guardians based on the protocols detailed by Oyedeji et al. [21] SES 1 and 2 were considered high, SES 3 as middle, and SES 4 and 5 as low.

Season of diagnosis was defined as rainy (April to September) or dry (October to March) seasons based on southern Nigerian climate season expression as recently described by Tamunopriye et al. [10]

Dehydration was categorized as mild, moderate, and severe grades based on the guidelines recommended by the American Academy of Pediatrics. [22]

Age was arbitrarily stratified into four age-groups $(\leq 5$ years, 6-10 years, $11-15$ years, and $\geq 16$ years).

Default to follow-up was defined as permanently missing clinic appointments following discharge from the hospital or following the last clinic visit exclusive of death or referral to other clinics within/outside of the hospital.

\subsection{Data Handling and Analysis}

Data was initially inputted into Statistical Package for Social Science software version 21 (IBM Corp., Armonk, NY, USA). Thereafter, the inputted data was reviewed, properly validated, coded, transformed into a specially designed template to be ideal for the computer input process, and subsequently analyzed using simple descriptive statistics.

\section{Results}

During the studied period (2003-2018), 45,533 pediatric cases were managed through various units in the study center with nine (9) cases of PDM diagnosed, giving an overall PDM prevalence of $0.20 / 1000$. All nine $(100 \%)$ identified PDM cases were of TIDM type.

The mean $( \pm \mathrm{SD})$ age and random plasma glucose $(\mathrm{RPG})$ at presentation were $7.00 \pm 4.82$ (range 2-16 years) and $17.82 \pm 4.37$ (range 13.3-23.40 $\mathrm{mmol} / \mathrm{l}$ ), respectively (Table 1). Results of the descriptive statistics of the other metric variables (heart rate, respiratory rate, and temperature) are depicted in Table 1.

Depicted in Table 2, the majority of the diagnosed TIDM cases were females $(n=6 ; 66.7 \%)$, presented mostly through the clinic unit $(\mathrm{n}=7 ; 77.8 \%)$ and diagnosed during the rainy season $(\mathrm{n}=5 ; 55.6 \%)$ of the southern Nigerian climate expression (Table 2). The majority of the cases were $\leq 5$ years $(n=4 ; 44.4 \%)$ of age, dwelt in the urban center $(n=5 ; 55.6 \%)$, and of Ibibio ethnic group $(\mathrm{n}=5 ; 55.6 \%)$ (Table 2). DM history in a family relative was reported by $33.3 \%(n=3)$ of the cases of which $66.7 \%(n=2)$ and $33.3 \%(n=1)$ were of first-degree and second-degree relatives, respectively (Table 2).

Most ( $\mathrm{n}=4 ; 44.4 \%)$ of the parents/guardians of the nine (9) cases were of lower SES at diagnosis (Table 2). Dehydration was recorded among 8 (88.8) of the cases with 4 (44.4\%) each of moderate and severe grades, respectively (Table 2 ). UTI $(n=2 ; 22.2 \%)$ was the most pronounced co-morbid condition reported. Of the $2(22.2 \%)$ cases presenting at the emergency unit, one was diagnosed with DKA complicated by AKI, while the other had dehydration-associated AKI (Table 2).

Of the seven (7) who presented/diagnosed in the clinic, 6 (66.7\%) defaulted from clinic appointments following DM diagnosis (Table 2). Of the two (2) who presented through the emergency unit, one (1) who presented in DKA complicated with AKI was lost to follow-up following discharge to the endocrine clinic, while the other with dehydration-associated AKI opted for discharge against medical advice (DAMA) and was also lost follow-up (Table 2).

Depicted in Table 3, $100 \%(n=9)$ of the cases presented with polyuria/polydipsia, seconded by generalized body weakness $(\mathrm{n}=8 ; 88.9 \%)$, and weight loss $(\mathrm{n}=7 ; 77.8 \%)$ (Table 3 ). The duration of polyuria (mean: $43.78 \pm 8.58$; range: $7-84$ days) was the highest and most prolonged compared to other reported symptoms at diagnosis (Table 3 ).

In Table 4, $5(55.6 \%)$ of the diagnosed cases had various abnormal anthropometric parameters at diagnosis. One (1) was moderately wasted and severely underweight/stunted, one (1) was moderately underweight/stunted, one (1) was severely stunted, while two (2) were overweight for age/sex (Table 4). Hence, three $(33.3 \%)$ were concurrently underweight/stunted while the other two $(22.2 \%)$ were both overweight.

Table 1. Baseline clinical/laboratory variables at diagnosis.

\begin{tabular}{llll}
\hline Variables & $\mathbf{n}(\mathbf{\%})$ & $\mathbf{M} \pm$ SD & Range \\
\hline Age, years & $9(100)$ & $7.00 \pm 4.82$ & $2-16$ \\
Temperature, ${ }^{\circ} \mathrm{C}$ & $9(100)$ & $37.48 \pm 0.99$ & $36.4-37.48$ \\
Heart/pulse rate, bpm & $8(88.9)$ & $89.56 \pm 5.90$ & $79.0-138.0$ \\
Respiratory rate, cpm & $9(100)$ & $23.22 \pm 6.49$ & $14.00-37.00$ \\
RPG, mmol/1 & $9(100)$ & $16.72 \pm 3.83$ & $13.30-23.40$ \\
\hline
\end{tabular}

SD: standard deviation; RPG: random plasma glucose; bpm: beats per minute; cpm: cycles per minute; mmol/l: milimole per liter.

Table 2. Distributions of the clinical/demographic stratifications at diagnosis.

\begin{tabular}{llll}
\hline Variables & Stratifications & N & \% \\
\hline \multirow{2}{*}{ Mode of presentation } & Via emergency unit & 2 & 22.2 \\
& Via clinic unit & 7 & 77.8 \\
Season of DM diagnosis & Dry & 4 & 44.4 \\
\multirow{2}{*}{ Gender } & Rainy & 5 & 56.6 \\
& Male & 3 & 33.3 \\
\hline
\end{tabular}




\begin{tabular}{|c|c|c|c|}
\hline Variables & Stratifications & $\mathbf{N}$ & $\%$ \\
\hline \multirow{4}{*}{ Age-groups, years } & $\leq 5$ & 4 & 44.4 \\
\hline & $6-10$ & 3 & 33.3 \\
\hline & $11-15$ & 1 & 11.1 \\
\hline & $\geq 16$ & 1 & 11.1 \\
\hline \multirow{2}{*}{ Place of residence } & Rural & 4 & 44.4 \\
\hline & Urban & 5 & 55.6 \\
\hline \multirow{4}{*}{ Ethnic groups } & Ibibio & 5 & 55.6 \\
\hline & Annang & 2 & 22.6 \\
\hline & Efik & 1 & 11.1 \\
\hline & Igbo & 1 & 11.1 \\
\hline \multirow{4}{*}{$\begin{array}{l}\text { DM family history } \\
\text { Degree of positive DM family history }\end{array}$} & Negative family history & 6 & 66.7 \\
\hline & Positive family history & 3 & 33.3 \\
\hline & First-degree relative & 2 & 66.7 \\
\hline & Second-degree relative & 1 & 33.3 \\
\hline \multirow{3}{*}{ Parents'/guardians' SES } & Higher & 2 & 22.2 \\
\hline & Middle & 3 & 33.3 \\
\hline & Lower & 4 & 44.4 \\
\hline \multirow{3}{*}{ Dehydration status } & None & 1 & 11.1 \\
\hline & Moderate & 4 & 44.4 \\
\hline & Severe & 4 & 44.4 \\
\hline \multirow{4}{*}{ Co-morbid conditions } & Pneumonia & 1 & 11.1 \\
\hline & UTI & 2 & 22.2 \\
\hline & Malaria & 1 & 11.1 \\
\hline & Gastroenteritis & 1 & 11.1 \\
\hline \multirow{2}{*}{ Complications } & DKA complicated with AKI & 1 & 11.1 \\
\hline & Dehydration-induced AKI & 1 & 11.1 \\
\hline \multirow{3}{*}{ Outcome } & Default to clinic follow-ups & 6 & 66.7 \\
\hline & DAMA & 1 & 11.1 \\
\hline & Discharged, thereafter lost to follow-up & 1 & 11.1 \\
\hline
\end{tabular}

DM: diabetes mellitus; SES: socioeconomic status; UTI: Urinary tract infection.

DKA: Diabetic ketoacidosis: AKI: Acute kidney injury; DAMA: Discharged against medical advice.

Table 3. Presenting symptoms at diagnosis.

\begin{tabular}{lllll}
\hline Symptoms & $\mathbf{n}$ & $\mathbf{\%}$ & Duration of symptoms, day Mean \pm SD & Range, duration of symptoms, days \\
\hline Polyuria & 9 & 100 & $43.78 \pm 8.58$ & $7-84$ \\
Polydipsia & 9 & 100 & $27.11 \pm 3.79$ & $5-56$ \\
Weakness & 8 & 88.9 & $13.78 \pm 3.80$ & $3-21$ \\
Weight loss & 7 & 77.8 & $30.29 \pm 4.74$ & $14-56$ \\
Vomiting \pm nausea & 5 & 55.6 & $4.70 \pm 2.1$ & $1-7$ \\
Abdominal pain & 5 & 55.6 & $5.20 \pm 1.66$ & $2-10$ \\
Polyphagia & 4 & 44.4 & $35.50 \pm 7.84$ & $14-56$ \\
Fever & 4 & 44.4 & $4.50 \pm 1.90$ & $3-7$ \\
Breathlessness & 2 & 22.2 & $2.00 \pm 1.40$ & $1-3$ \\
Altered sensorium & 2 & 22.2 & $5.00 \pm 2.20$ & $3-7$ \\
Enuresis & 2 & 22.2 & $17.50 \pm 4.84$ & $7-28$ \\
\hline
\end{tabular}

SD: standard deviation.

Table 4. Anthropometric parameters at diagnosis.

\begin{tabular}{lllllllll}
\hline S/N & Gender & Age, $\mathbf{y r s}$ & Wt, $\mathbf{~ g}$ & $\mathbf{H t}, \mathbf{c m}$ & $\mathbf{H A Z}$ & $\mathbf{W A Z}$ & WHZ & BMIZ \\
\hline 1 & F & 2 & 6.6 & 60 & -5.39 & -4.70 & -2.44 & -1.59 \\
2 & F & 2 & 11.0 & 85 & -1.03 & -0.69 & -0.22 & -0.11 \\
3 & F & 3 & 13.0 & 92 & -1.73 & -0.84 & +0.31 & -0.31 \\
4 & F & 4 & 12.0 & 90 & -2.80 & -2.42 & -1.04 & -0.80 \\
5 & M & 8 & 27.0 & 130 & +0.16 & +0.18 & - & +0.09 \\
6 & M & 7 & 20.0 & 116 & -1.38 & -1.25 & - & -0.51 \\
7 & M & 9 & 36 & 135 & +0.35 & +1.46 & - & +1.75 \\
8 & F & 12 & 50.0 & 146 & -1.04 & - & - & +1.60 \\
9 & F & 16 & 37 & 136 & -3.91 & - & - & -0.26 \\
\hline
\end{tabular}

yrs: years; Wt: weight; Ht: height; HAZ: height for age $\mathrm{Z}$ score; WAZ: weight for age $\mathrm{Z}$ score.

WHZ: weight for height $Z$ score; BMIZ: body mass index $Z$ score; kg: kilogram; cm: centimeter. 


\section{Discussion}

In the present study, we had retrospectively reviewed the demographic, clinical, and laboratory characteristics of nine (9) subjects with PDM who had presented at the University of Uyo Teaching Hospital, Akwa Ibom State, south-south Nigeria over 15 years.

The prevalence of PDM among our studied population was $0.2 / 1000$, which is in accord with the rate recorded in a similar study reported from Abakaliki (0.1/1000), south-eastern Nigeria, and Sokoto (0.33/1000), north-eastern Nigeria. [7, 9] The low prevalence is in keeping with the pattern of PDM reported in Sub-Sahara Africa. [23, 24] However, our reported prevalence was lower than the rates, which ranges between $1.4 / 1000$ to $10.1 / 1000$, recorded in most other Nigerian studies. $[5,6,10-13]$ This may be adduced to the high patronage for informal healthcare services among the inhabitants within the studied region [25] Furthermore, the entire nine (9) PDM cases were all of type $1 \mathrm{DM}$ variant consistent with other reports within the studied region. [5-13]

Most of the PDM cases were females with is in tandem with most recent Nigerian reports and those documented in the western populations. [5-12] This has been attributed to the increased susceptibility to autoimmune disorders, which defines T1DM, in females. 26 Most of our studied population were $\leq 5$ years at diagnosis which is at variance with most reports in the literature. [9-13, 24] These previous studies [9$13,24]$ had documented a peak incidence of type 1 PDM within the 10-14 age-groups which coincides with the onset of puberty-induced hormonal impact on insulin sensitivity. $[27,28]$ The incidence of PDM in $\leq 5$-year-olds is clinically significant because diabetes-related symptoms at this age are not usually classic which may further worsen symptoms and diabetic complications. [29]

The majority $(\mathrm{n}=7 ; 77.8 \%)$ presented via the clinic unit compared to only $22.2 \%(\mathrm{n}=2)$ subjects who presented via the emergency unit (one with DKA complicated by AKI and the other with dehydration-induced AKI). This finding is in contrast with most reports on PDM in Nigeria and most other parts of the developing countries. [5-13, 24] Presentation mostly in the emergency unit with DM complications (usually with DKA) has been the norm in most other reports in Nigeria and developing societies. [5-13] The basis for this unusual finding in the current study is unknown but remains an area to be explored in future research. However, being a tertiary hospital-based retrospective study, it likely that patients had sort alternative primary/secondary healthcare services, opted for non-orthodox therapies, died at home, or misdiagnosed in the hospital.

In parallel with a recent finding in a similar study documented by Tamunopriye et al, most were diagnosed during the rainy season which is the coldest season of the studied region. [10] Similar observation was recently documented in Poland. [30] It is believed that the rainy cold season increases the risk of viral infections and reduces sunderived vitamin $\mathrm{D}$ acquisition; factors that are known to trigger islet autoimmunity with progression to overt PDM. [30] Most of our subjects dwelt in urban centers at diagnosis. This finding is concordant with similar observations documented by John et al from north-central Nigeria and Hayes et al from Western Australia. [8, 31] The dominance of urban residents in the current study may indicate enhanced exposures to other environmental toxins and pollutants known to trigger PDM in genetically susceptible children. [32]

Based on ethnicity, cases from the Ibibio ethnic group dominated among the PDM subjects. No comparable Nigerian-based pediatric study was found in the literature to evaluate this finding and no reason can be adduced to the dominance by the Ibibio ethnic from the current study due to its limited sample size. Nevertheless, the Ibibio ethnic group is the most populous in the studied region which may explain their dominance.

In tandem with local reports documented by Anochie et al (south-south Nigeria), Adeleke et al (north-west Nigeria), John et al (north-central Nigeria), Tamunopriye et al (Southsouth Nigeria), and Idris et al (North-west Nigeria), most of the studied subjects were of lower SES at diagnosis. [5, 6, 8, $10,12]$ In contrast, a higher SES was associated with PDM incidence among Australian children [31] Lower SES may adversely impact the capacity to financially cope with PDM care, thereby worsening the disease burden, as recently documented. [33]

DM family history rate, a major risk factor for PDM, ranging from $11.1 \%$ to $70 \%$ had been reported in various Nigerian studies $[5,8,12]$, which agrees with our $33.3 \%$ rate. However, these previous studies $[5,8,12]$ did not define the degree of family relationships with their PDM subjects. In the current study, we recorded $66.7 \%$ rate of DM family history in first-degree relatives which is higher than the rates reported in sub-Sahara Africa and the western populations $[24,34]$.

The higher rate may be because subjects with family history survive more often than those with no family history, due to greater awareness in families where the disease already exist. [24]

The predominant symptoms at presentation were polyuria (100\%), polydipsia $(100 \%)$, weight loss $(88.9 \%)$, and generalized body weakness (77.8\%) which are classic DM symptoms previously reported by Tamunopriye et al and Umar et al and other Nigerian studies among children presenting with PDM [5-13] In terms of the symptoms and their durations, polyuria remains the most prolonged which reflects the duration of DM evolution before presentation since polyuria is one of the earliest clinical manifestations of DM in children. [1,35]

In line with a previous local report documented by Adeleke et al, infection was the most co-morbid condition recorded among the studied subjects with UTI predominating (22.2\%). [6] Though our reported UTI rate $(22.2 \%)$ was lower than the rate documented by Adeleke et al (36.4\%). [6] Infection is a common finding among newly 
diagnosed PDM subjects which is reportedly related to the persistent glycosuria and aberrations of immune responses in DM. [36] UTI may act as a stressor, via increased stressed-induced secretion of the counter-regulatory hormones resulting in relative insulin deficiency, which could ultimately trigger DM in these subjects with already depleted beta cells.

The incidence of PDM in children, especially in resourcepoor settings such as sub-Sahara Africa, can be influenced by malnutrition particularly undernutrition [37, 38] However, only three $(33.3 \%)$ of our subjects were concurrently underweight/stunted while only two $(22.2 \%)$ were solely overweight at diagnosis. The rates of nutritional disorders observed in the current study are lower than the rates recently documented by Tamunopriye et al and indicate that malnutrition might not have played a major role in DM incidence among our studied subjects [10] Similar conclusion had been documented by John et al from North-central Nigeria. [8]

The outcome of our studied subjects was very discouraging with very high rates of defaults to clinic follow-ups. This finding is consistent with previous reports, documented by Ibekwe et al, Ugege et al, and Idris et al, in similar Nigerian studies [7, 9] This trend also mirrors the findings in many other parts of the developing societies [33, 39] The reason for this discouraging finding in the current study could be adduced to the low SES of the studied subjects. However, Ugege et al had generally attributed this to frustration, financial constraints, inadequate parent/patient education, underlying poverty, and poor standard of care. [9]

The study was limited by some factors that warrant mentioning and hence, must be interpreted in that context. First, the study was limited by its small sample size. Secondly, due to a lack of relevant data, subjects were diagnosed based on history, clinical findings, and glycemic status without the standard autoimmune and genetic markers for T1DM, which could have led to misclassification/misdiagnosis. Thirdly, since the data were retrospectively acquired, there is also a likelihood of missing data. Finally, the study was solely hospital-based, therefore, its findings might not reflect the general population in the studied region.

\section{Conclusion}

The prevalence of PDM was relatively low among the studied population in the current study with the $\leq 5$-year-olds, females, urban-dwellers, and children of lower socioeconomic backgrounds predominating. Most of the PDM subjects surprisingly presenting through the clinic unit with prolonged classic DM clinical features. Under-nutrition was documented among a few of the PDM subjects. The rate of default to follow-up following PDM diagnosis was discouragingly very high. Hence, the study findings could serve as health policy targets by various concerned stakeholders within the studied region.

\section{Ethical Statement}

The study protocol was approved by the Institutional (UUTH) Research Ethics Committee (2019-330).

\section{Funding}

The study was equally funded by the authors.

\section{Conflict of Interest}

There are no conflicts of interest to declare regarding this study.

\section{Acknowledgements}

The authors appreciate the assistance of all Mr. Junior Kelvin Ebbah and Miss Uchechi Olivia Njoku of the Department of Chemical Pathology, UUTH during the period of this study.

\section{References}

[1] Mayer-Davis EJ, Kahkoska AR, Jefferies C, Dabelea D, Balde $\mathrm{N}$, Gong CX, et al. ISPAD Clinical Practice Consensus Guidelines 2018: Definition, epidemiology, and classification of diabetes in children and adolescents. Ped diabetes. 2018; 19 7-19.

[2] Della Manna T, Setian N, Savoldelli RD, Guedes DR, Kuperman H, Menezes Filho HC, et al. Diabetes mellitus in childhood: an emerging condition in the 21 st century. Rev. Assoc. Med. Bras. 2016; 62 (6): 594-601.

[3] Dabelea D, Stafford JM, Mayer-Davis EJ, D'Agostino Jr R, Dolan L, Imperatore G, et al. Search for Diabetes in Youth Research Group: association of type 1 diabetes vs type 2 diabetes diagnosed during childhood and adolescence with complications during teenage years and young adulthood. JAMA. 2017; 317 (8): 825-35.

[4] Dabelea D, Mayer-Davis EJ, Saydah S, Imperatore G, Linder B, Divers J, et al. Prevalence of type 1 and type 2 diabetes among children and adolescents from 2001 to 2009. Jama. 2014; 311 (17): 1778-86.

[5] Anochie IC, Opara PI, Eke FU. Childhood diabetes mellitus in Port Harcourt: Any change in prevalence and outcome PMJ. 2008; 2: 126-129.

[6] Adeleke SI, Asani MO, Belonwu RO, Gwarzo GD, Farouk ZL. Childhood diabetes mellitus in Kano, Northwest Nigeria. Niger J Med. 2010; 19: 145-7.

[7] Ibekwe MU, Ibekwe RC. Pattern of Type 1 diabetes mellitus in Abakaliki, Southeastern, Nigeria. Pediatric oncall. 2011; 8: 59-62.

[8] John C, Abok II, Yilgwan C. Clinical profile of childhood type 1 diabetes mellitus in Jos, Nigeria. Afr J Diab Med. 2013; 21 (1): 11-3.

[9] Ugege O, Ibitoye PK, Jiya NM. Childhood diabetes mellitus in Sokoto, north-western Nigeria: A ten-year review. Sahel Med J 2013; 16: 97-101. 
[10] Tamunopriye J, Iroro Y. The pattern of presentation and trends of childhood diabetes mellitus in Port Harcourt, Southern Nigeria. J Adv Med Med Res. 2015; 5 (2): 247-53.

[11] Umar UI. Pattern of presentation of Type 1 diabetic patients in Kano, Nigeria. Niger J Basic Clin Sci 2016; 13: 85-8.

[12] Idris UA. Childhood diabetes mellitus in a rural tertiary hospital in North-West Nigeria. CHRISMED J Health Res 2018; 5: 123-6.

[13] Umar UI, Muhammed IL, Aliyu I. Retrospective review of presentation of newly diagnosed children with diabetes mellitus in a Nigerian rural setting. Med J DY Patil Vidyapeeth 2019; 12: 490-4.

[14] Ekpenyong CE, Akpan UP, Ibu JO, Nyebuk DE. Gender and age-specific prevalence and associated risk factors of type 2 diabetes mellitus in Uyo Metropolis, Southeastern Nigeria. Diabetologia Croatica 2012; 41: 17-23.

[15] Idem I, Ukoh G, Ekott E. Prevalence and Risk Factors of Diabetes Mellitus in Eket, South-South Nigeria. J Biotech Biochem. 2017; 3 (3): 32-5.

[16] Wolfsdorf JI, Glaser N, Agus M, Fritsch M, Hanas R, Rewers A, Sperling MA, et al. ISPAD Clinical Practice Consensus Guidelines 2018: Diabetic ketoacidosis and the hyperglycemic hyperosmolar state. Pediatr Diabetes. 2018; 19 (Suppl. 27): $155-77$.

[17] KDIGO Acute Kidney Injury Working Group. KDIGO clinical practice guideline for acute kidney injury. Kidney Int Suppl. 2012; 2: 1-138.

[18] Hursh BE, Ronsley R, Islam N, Mammen C, Panagiotopoulos C. Acute kidney injury in children with type 1 diabetes hospitalized for diabetic ketoacidosis. JAMA Pediatr. 2017; 171 (5):e170020.

[19] WHO Anthro for personal computers, version 3.2.2, 2011: Software for assessing growth and development of the world's children. Geneva: WHO, 2010.

[20] WHO AnthroPlus for personal computers: Software for assessing growth of the world's children and adolescents. Geneva: WHO, 2009.

[21] Oyedeji GA. Socioeconomic and cultural background of hospitalized children in Ilesha. Nig. J Paed. 1985; 12: 111-7.

[22] Practice parameter: the management of acute gastroenteritis in young children. American Academy of Pediatrics, Provisional Committee on Quality Improvement, Subcommittee on Acute Gastroenteritis. Pediatrics 1996; 97: 424-435.

[23] Patterson CC, Karuranga S, Salpea P, Saeedi P, Dahlquist G, Soltesz G, et al. Worldwide estimates of incidence, prevalence, and mortality of type 1 diabetes in children and adolescents: Results from the International Diabetes Federation Diabetes Atlas. Diabetes Res Clin Pract. 2019; 157: 107842. DOI:.org/10.1016/j.diabres.2019.107842.

[24] Jasem D, Majaliwa ES, Ramaiya K, Najem S, Swai AB, Ludvigsson J. Incidence, prevalence and clinical manifestations at onset of juvenile diabetes in Tanzania. Diabetes Res Clin Pract. 2019; 156: 107817. DOI.org/10.1016/j.diabres.2019.107817.

[25] Idung AU, Jombo HE, Ekanem AM, Quality of Life in Primary Care Patients Who Use Complementary and
Alternative Medicine in Uyo, South-South, Nigeria. Int J Innov Healthcare Res. 2018; 6 (1): 29-39.

[26] Ngo ST, Steyn FJ, McCombe PA. Gender differences in autoimmune disease. Frontiers in neuroendocrinology. 2014 Aug 1; 35 (3): 347-69.

[27] Ludvigsson J. Why diabetes incidence increases--a unifying theory. Ann N Y Acad Sci. 2006; 1079: 374-382. doi: 10.1196/annals. 1375.058 .

[28] Jeffery AN, Metcalf BS, Hosking J, Streeter AJ, Voss LD, Wilkin TJ. Age before stage: insulin resistance rises before the onset of puberty: a 9-year longitudinal study (Early Bird 26). Diabetes Care. 2012; 35 (3): 536-541. doi: 10.2337/dc11-1281.

[29] Al-Fifi SH. The relation of age to the severity of Type I diabetes in children. J Family Community Med. 2010; 17 (2): $87-90$

[30] Szypowska A, Ramotowska A, Wysocka-Mincewicz M, Mazur A, Lisowicz L, Beń-Skowronek I et al. Seasonal variation in month of diagnosis of polish children with type 1 diabetes-a multicenter study. Exp Clin Endocrinol Diabetes. 2019; 127 (05): 331-5.

[31] Haynes A, Bulsara MK, Bower C, Codde JP, Jones TW, Davis EA. Independent effects of socioeconomic status and place of residence on the incidence of childhood type 1 diabetes in Western Australia. Pediatr Diabetes. 2006; 7 (2): 94-100. DOI: $10.1111 /$ j.1399-543X.2006.00153.x.

[32] Sheehan A, Freni Sterrantino A, Fecht D, Elliott P, Hodgson S. Childhood type 1 diabetes: an environment-wide association study across England. Diabetologia. 2020; 63 (5): 964-976. DOI: 10.1007/s00125-020-05087-7.

[33] Atun R, Davies JI, Gale EA, Bärnighausen T, Beran D, Kengne AP, Levitt NS, Mangugu FW, Nyirenda MJ, Ogle GD, Ramaiya K. Diabetes in sub-Saharan Africa: from clinical care to health policy. Lancet Diab Endocrinol. 2017; 5 (8): 622-67.

[34] Turtinen M, Härkönen T, Parkkola A, Ilonen J, Knip M, Finnish Pediatric Diabetes Register. Characteristics of familial type 1 diabetes: effects of the relationship to the affected family member on phenotype and genotype at diagnosis. Diabetologia. 2019; 62 (11): 2025-39.

[35] Mokashi A, Young M. When you suspect diabetes in a child. Can Fam Physician. 2018; 64 (1): 32-5.

[36] Calliari LE, Almeida FJ, Noronha RM. Infections in children with diabetes. Jornal de Pediatria (Versão em Português). 2020; 96: 39-46.

[37] Balcha SA, Phillips DI, Trimble ER. Type 1 Diabetes in a Resource-Poor Setting: Malnutrition Related, Malnutrition Modified, or Just Diabetes? Curr Diab Rep. 2018; 18 (7): 47. DOI: $10.1007 / \mathrm{s} 11892-018-1003-7$.

[38] Uwaezuoke SN. Childhood Diabetes Mellitus and the 'Double Burden of Malnutrition': An Emerging Public Health Challenge in Developing Countries. J Diabetes Metab 2015; 6: 597. DOI: $10.4172 / 2155-6156.100059$.

[39] Tino S, Wekesa C, Kamacooko O, Makhoba A, Mwebaze R, Bengo S, et al. Predictors of loss to follow up among patients with type 2 diabetes mellitus attending a private not for profit urban diabetes clinic in Uganda-a descriptive retrospective study. BMC Health Serv Res. 2019; 19 (1): 598. DOI: 10.1186/s12913-019-4415-4. 